\title{
Early massive transfusion in trauma patients: Canadian single-centre retrospective cohort study
}

\section{Transfusion précoce massive chez les patients traumatisés: Une étude de cohorte rétrospective dans un centre canadien}

\author{
Tushar D. Mahambrey, MBBS - Robert A. Fowler, MD - Ruxandra Pinto, PhD • \\ Terry S. Smith, MD · Jeannie L. Callum, MD · Nagib S. Pisani, DC • \\ Sandro B. Rizoli, MD, PhD · Neill K. J. Adhikari, MDCM
}

Received: 1 March 2009/Accepted: 9 July 2009/Published online: 30 July 2009

(C) Canadian Anesthesiologists' Society 2009

\begin{abstract}
Purpose To determine associations between red blood cell $(R B C)$ transfusion and early and late clinical outcomes in massively transfused adult trauma patients.

Methods A retrospective cohort study (1992-2001) including 260 patients receiving $\geq 10 \mathrm{RBC}$ units $\leq 24 \mathrm{hr}$ after admission to a university-affiliated trauma centre. We
\end{abstract}

R. A. Fowler and N. K. J. Adhikari contributed equally to this study.

T. D. Mahambrey, MBBS - R. A. Fowler, MD - R. Pinto, PhD .

T. S. Smith, MD - N. S. Pisani, DC - S. B. Rizoli, MD, PhD .

N. K. J. Adhikari, MDCM

Department of Critical Care Medicine, Sunnybrook Health

Sciences Centre, University of Toronto, Toronto, ON, Canada

R. A. Fowler, MD - T. S. Smith, MD - S. B. Rizoli, MD, PhD .

N. K. J. Adhikari, MDCM

Interdepartmental Division of Critical Care, University

of Toronto, Toronto, ON, Canada

J. L. Callum, MD

Department of Clinical Pathology, Sunnybrook Health Sciences

Centre, University of Toronto, Toronto, ON, Canada

Present Address:

T. D. Mahambrey, MBBS

Department of Critical Care Medicine, St Helens and Knowsley

Teaching Hospitals NHS Trust and Tertiary Burns Centre,

Prescot, Liverpool, UK

Present Address:

N. S. Pisani, DC

Toronto Healthcare Rehabilitation Centre, Toronto, Canada

\section{N. K. J. Adhikari, MDCM ( $\square)$}

Department of Critical Care Medicine, Sunnybrook Health

Sciences Centre, University of Toronto, Room D1.08, 2075

Bayview Avenue, Toronto, ON M4N 3M5, Canada

e-mail: neill.adhikari@utoronto.ca extracted demographic and clinical data and used multivariable regression to determine independent effects of $R B C$ transfusion on clinical outcomes.

Results Patients had a high (mean [standard deviation]) injury severity score (ISS) (42.5 [15.1]), a high admission sequential organ failure assessment (SOFA) score (8.4 [3.8]), and a high hospital mortality (58.5\%). They received 38 (25-64) (median [interquartile range]) blood components within $48 \mathrm{hr}$, including 19 (14-28) RBC units. For 143 patients surviving $\geq 48 \mathrm{hr}$, the maximum SOFA score was associated with RBC units transfused before $48 \mathrm{hr}$ (linear regression beta coefficient 0.075, $P<0.0001$ ), lower nadir hemoglobin before $48 \mathrm{hr}(0.034, P=0.03)$, age (0.032, $P=0.015)$, and admission SOFA (0.59, $P<0.0001$ ). The RBC units transfused by $48 \mathrm{hr}$ were not associated with either hospital mortality $(n=35)$ among patients surviving $\geq 48 \mathrm{hr}$ (independent predictors, age [logistic regression odds ratio $(O R) 1.06,95 \%$ confidence interval 1.03-1.10], ISS [OR 1.07, 1.02-1.13], and maximum SOFA score [OR 1.56, 1.27-1.93]) or 48-hr mortality $(n=117)$ (independent predictors, admission SOFA [1.65, 1.45-1.88] and later year of hospital admission [OR 1.15, 1.02-1.29]).

Conclusions Hospital mortality is high among massively transfused trauma patients. Among early survivors, 48-hr $R B C$ transfusion volume is associated with increased organ dysfunction, but not hospital mortality. Also, it is not associated with 48-hr mortality. Future research should continue to explore methods to improve hemostasis and minimize the need for RBC transfusion.

\footnotetext{
Résumé

Objectif Déterminer les associations qui existent entre la transfusion d'érythrocytes et les devenirs cliniques
} 
précoces et tardifs de patients traumatisés adultes ayant reçu une transfusion massive.

Méthode Une étude de cohorte rétrospective (19922001) portant sur 260 patients ayant reçu $\geq 10$ unités d'érythrocytes $\leq 24$ heures après leur admission à un centre universitaire de traumatologie. Nous avons extrait les données démographiques et cliniques et utilisé une analyse par régression multivariée pour déterminer les effets indépendants de la transfusion d'érythrocytes sur les devenirs cliniques.

Résultats Les patients avaient un score de gravité du traumatisme élevé (ISS) (moyenne [écart type]) (42,5 [15,1]), un score de SOFA (sequential organ failure assessment) élevé à l'admission $(8,4$ [3,8]), et un taux élevé de mortalité à l'hôpital (58,5\%). Les patients ont reçu 38 (25-64) (médiane [écart interquartile]) composants sanguins en 48 heures, y compris 19 (14-28) unités d'érythrocytes. Pour les 143 patients ayant survécu $\geq 48$ heures, le score de SOFA maximal était associé à des unités d'érythrocytes transfusées avant 48 heures (coefficient bêta de régression linéaire 0,075, $P<0,0001$ ), une concentration plus faible d'hémoglobine avant 48 heures (0,034, $P=0,03)$, l'âge $(0,032, P=0,015)$, et le score de SOFA à l'admission $(0,59, P<0,0001)$. Les unités d'érythrocytes transfusées à 48 heures n'ont pas été associées à la mortalité à l'hôpital $(n=35)$ chez les patients survivant $\geq 48$ heures (prédicteurs indépendants, âge [rapport de cotes $(R C)$ de régression logistique 1,06, intervalle de confiance $95 \%$ 1,03-1,10], ISS [RC 1,07, 1,02-1,13], et un score de SOFA maximal [RC 1,56, 1,27-1,93]) ou une mortalité à 48 heures $(n=117)$ (prédicteurs indépendants, score SOFA à l'admission [1,65, 1,45-1,88] et l'année d'admission à l'hôpital [RC 1,15, 1,02-1,29]).

Conclusion La mortalité à l'hôpital est élevée chez les patients traumatisés recevant des transfusions massives. Chez les survivants précoces, le volume de transfusion d'érythrocytes à 48 heures est associé à une dysfonction des organes élevée, mais pas à la mortalité intrahospitalière. En outre, il n'est pas associé à la mortalité à 48 heures. Les recherches futures devraient continuer d'explorer les méthodes permettant d'améliorer l'hémostase et de minimiser le besoin de transfusion d'érythrocytes.

Worldwide, injuries are a significant cause of death and disability-adjusted life years lost, ${ }^{1}$ including in Canada where about 2 million injuries annually lead to $\$ 4.2$ billion in direct health care costs. ${ }^{2}$ Resuscitation of severe trauma often mandates blood component transfusion, with massive transfusion defined as the administration of at least 10 red blood cell units within the first $24 \mathrm{hr}^{3}$ Among traumatically injured patients, those with massive hemorrhage account for $80 \%$ of early mortality ${ }^{4}$ and $40 \%$ of in-hospital mortality. ${ }^{5}$ Transfusion of red blood cells in trauma patients has also been associated with acute lung injury, ${ }^{6,7}$ infection, ${ }^{8-10}$ and multiple organ failure. ${ }^{10,11}$

To inform local hospital efforts to standardize transfusion practices for trauma patients, we designed a quality improvement project to describe the effects of early transfusion practices for massively bleeding trauma patients. We examined the independent association linking red blood cell transfusion volume before $48 \mathrm{hr}$ and (1) organ dysfunction (primary outcome), as defined by the sequential organ failure assessment (SOFA) score ${ }^{12}$; (2) hospital mortality; (3) length of stay in the intensive care unit (ICU) (all among patients surviving the initial $48 \mathrm{hr}$ ); and (4) 48-hr mortality among all patients. We were particularly interested in late effects of red blood cell transfusion among 48-hr survivors because multiple organ failure is the most common cause of death in this group, compared with severe head injury and hemorrhage, which are the most common early causes of death. ${ }^{5}$

\section{Methods}

Setting and patients

Sunnybrook Health Sciences Centre is a university-affiliated hospital and trauma centre. We initiated this study in 2003 and identified all adult trauma patients from 1 January 1992 to 31 December 2001 who were age $\geq 15 \mathrm{yr}$ and massively transfused ( $\geq 10$ units of red blood cells) within the first $24 \mathrm{hr}$ of presentation to hospital, regardless of survival to ICU admission. The dataset did not include patients admitted after 2001. We selected the 10-year timeframe (1992-2001) for data collection because the hospital's trauma registry and blood bank database included cases from this period and available research personnel could feasibly collect data for identified cases. Although massive transfusion is variably defined, our definition is common ${ }^{3,13}$ and has been locally adopted. During the period of the study, the hospital had approximately 450 acute care beds with a median of 664 (range, 467-864) admissions per year due to trauma; 488 (range, 344-628) of the admissions had an injury severity score (ISS) $\geq 16 .{ }^{14}$ During resuscitation, bleeding trauma patients were generally transfused according to estimated blood loss and in response to anemia, thrombocytopenia, or abnormal coagulation tests, as defined by the individual trauma surgeon, anesthesiologist, or intensivist. Patients meeting selection criteria were identified using the hospital's trauma registry and verified using an independent hospital blood bank database (Hemocare $^{\mathrm{TM}}$, Mediware Information Systems Inc., Oakbrook, IL and Lenexa, KS, USA). The hospital research ethics board approved the 
study as a quality improvement project and waived the need for patient informed consent.

\section{Data collection}

One data collector reviewed electronic and paper clinical records and recorded the following data: demographic information (age, sex, admission date); injury data (ISS, mechanism of injury); laboratory values (hemoglobin, platelet count, international normalized ratio [INR] and fibrinogen); and transfusion data (units of red blood cells, pooled platelets, fresh frozen plasma, and cryoprecipitate) for the first $48 \mathrm{hr}$ after presentation; daily physiologic data necessary to calculate the SOFA score ${ }^{12}$; and outcome variables (48-hr and hospital mortality and disposition for survivors). We did not collect data on pre-transfusion storage time of red blood cell units or on turnaround time from ordering to administration of blood components.

The SOFA score measures organ dysfunction (respiratory, coagulation, hepatic, cardiovascular, central nervous system, and renal; range, 0-24, with a higher score indicating more severe organ dysfunction) in critically ill patients. ${ }^{12}$ Although initially developed to describe organ dysfunction over time, the maximum SOFA strongly predicts mortality in medical-surgical critically ill patients. ${ }^{15,16}$ For patients dying before ICU admission, the SOFA score was calculated using available data from the emergency department or operating room.

\section{Statistical analysis}

The number of cases during the study period determined the sample size. Data were summarized using means and standard deviations (SD) or medians and interquartile ranges (IQR) for normally and non-normally distributed continuous variables, respectively, and percentages for discrete variables. For all multivariable analyses, we selected candidate predictor variables a priori based on hypotheses (partly supported by previous work) ${ }^{10,17-20}$ that major determinants of trauma outcomes included patient age and severity of initial injury and ensuing critical illness. We believed that models should adjust for year of hospital admission given the long time-span of the dataset.

We examined predictors of organ dysfunction and ICU length of stay in patients who survived to $48 \mathrm{hr}$ after admission. First, we used linear regression to determine whether organ dysfunction, as determined by the maximum SOFA score during ICU stay measured from day 3 of ICU admission, was independently associated with the amount of red blood cells transfused in the first $48 \mathrm{hr}$, after adjusting for confounders (age, sex, SOFA at ICU admission, and nadir hemoglobin before $48 \mathrm{hr}$ ) and effect modifiers (ISS and year of hospital admission). Sequential organ failure assessment data were available for $87 \%$ of patient-days for those surviving beyond $48 \mathrm{hr}$. Second, with death in ICU as a competing risk, we analyzed time to live ICU discharge using a Fine and Gray model to determine whether the amount of red blood cells transfused in the first $48 \mathrm{hr}$ independently predicted ICU length of stay among ICU survivors, adjusted for the same variables. ${ }^{21}$

We constructed two separate multiple logistic regression models to examine the association of red blood cell transfusion with mortality, one for mortality within $48 \mathrm{hr}$ among all patients and the other for hospital mortality among patients surviving at least $48 \mathrm{hr}$. Predictor variables for 48hr mortality included red blood cell units transfused by $48 \mathrm{hr}$ (main effect); age, sex, SOFA at ICU admission, and total blood components transfused by $48 \mathrm{hr}$ (confounders); and ISS and year of hospital admission (effect modifiers). We excluded nadir hemoglobin before $48 \mathrm{hr}$ from this analysis because patients who died within $48 \mathrm{hr}$ may have had fewer blood tests and thus would be less likely to have a low hemoglobin value compared with patients surviving to $48 \mathrm{hr}$. The multiple logistic regression model included all variables except total blood components transfused by $48 \mathrm{hr}$, which was highly collinear (Pearson correlation, 0.90) with red blood cell units transfused by $48 \mathrm{hr}$.

Predictor variables for hospital mortality among 48-hr survivors included red blood cell units transfused by $48 \mathrm{hr}$ (main effect); age, sex, SOFA at ICU admission, maximum SOFA during ICU stay (from first day of ICU admission to ICU discharge), nadir hemoglobin before $48 \mathrm{hr}$, and total blood components transfused by $48 \mathrm{hr}$ (confounders); and ISS and year of hospital admission (effect modifiers). Because the hospital mortality model contained few outcome events ( 35 deaths), we included only the five most clinically important variables in the main multiple logistic model (age, ISS, maximum SOFA during ICU stay, red blood cell units transfused by $48 \mathrm{hr}$, year of hospital admission), acknowledging that seven outcome events per variable is usually considered to be less than ideal. ${ }^{22}$ Based on a recent statistical simulation study suggesting that multiple logistic models perform adequately with as few as five events per variable, ${ }^{23}$ we conducted a sensitivity analysis by adding the variables of sex and nadir hemoglobin before $48 \mathrm{hr}$ to the model. We did not enter the variable of SOFA at ICU admission into either multivariable model because it was of less clinical interest and was collinear (Pearson correlation, 0.65) with maximum SOFA during ICU.

We did not have information for 12 patients regarding the number of red blood cell units transfused by $48 \mathrm{hr}$. For these patients, we substituted the missing values with the total number of red blood cell units transfused for the entire hospital stay; patients without missing data were transfused a median of $88 \%$ of all red blood cells transfused in hospital within the first $48 \mathrm{hr}$. We performed sensitivity 
analyses by removing these cases. Results did not change, except for the Fine and Gray model where we report both the primary analysis excluding patients with missing data and a secondary analysis including them.

We hypothesized that the effect of red blood cell transfusion might depend (1) on the year of hospital admission because general improvements in trauma care might attenuate any harmful effect of red blood cell transfusion; and (2) on ISS because any effects of red blood cells might be restricted to patients with less catastrophic injuries (lower ISS) and a lower baseline probability of mortality. Thus, for all models we tested for interactions (1) between red blood cell units transfused by $48 \mathrm{hr}$ and year; and (2) between red blood cell units transfused by $48 \mathrm{hr}$ and ISS. No significant two-way interactions were detected.

Absolute values of all correlation coefficients between independent variables in multiple linear and logistic regression models were less than 0.8, suggesting no multicollinearity. All a priori selected clinically important variables were entered and retained in the multivariable regression models. Results from univariable and multivariable models are presented. In the multiple logistic regression models, we examined lack of fit using the Hosmer-Lemeshow test, with the sample divided into equally populated deciles of estimated probability. We also assessed the linearity of the relationship between continuous predictor variables and the outcome. For the logistic regression models, we constructed plots of log odds of an outcome event $v s$ each binned continuous variable. For the Fine and Gray analysis, we constructed separate models for each binned continuous variable and plotted the coefficients $v s$ the bins. ${ }^{24}$ The residuals of the linear regression model were inspected for normality, homogeneity of variance, and evidence of a linear relationship with respect to each predictor variable; no departures from those assumptions were detected.

All tests were two-sided and statistical significance was declared for $P<0.05$. We used SAS ${ }^{\circledR}$ version 9.1 (SAS Institute, Inc., Cary, NC, USA) for all analyses, except for the Fine and Gray model, which was implemented using the function $\mathrm{cr}$ in the library cmprsk in the R statistical package, version 2.7.2 (R Foundation, available at http:// www.r-project.org).

Since the data of interest were routinely recorded in patient charts, we did not anticipate differential misclassification regarding exposures or outcomes. Given the relatively narrow population of interest and the number of exposures considered, we believed that multivariable regression would most efficiently address confounding variables. However, we anticipated that the problem of 'immortal time' would underestimate the odds ratio between red blood cell transfusion by $48 \mathrm{hr}$ and $48 \mathrm{-hr}$ mortality. ${ }^{25,26}$ This bias arises because patients must survive a period of time in order to receive a red blood cell transfusion, and it is appropriately corrected by conducting a time-to event analysis with red blood cell transfusion modelled as a time-dependent exposure. We did not record the exact time of death, precluding such an analysis. This bias would not affect our analyses restricted to patients surviving to $48 \mathrm{hr}$, in whom the variable of red blood cell transfusion by $48 \mathrm{hr}$ was already fixed.

\section{Results}

We identified 368 trauma patients who received $\geq 10$ red blood cell transfusions within $24 \mathrm{hr}$ of admission in the 10-year period from 1 January 1992 to 31 December 2001. After excluding patients due to missing laboratory data $(n=80)$, missing medical records $(n=14)$, unknown phlebotomy collection times $(n=12)$, and inability to link records among clinical databases $(n=2), 260$ patients remained in the analysis. Baseline data on the excluded patients are not available.

Patients were predominantly male $(68.1 \%)$ with a median age of 38 (IQR 26.5-62) and high ISS (mean 42.5, SD 15.1) (Table 1). The most common mechanism of injury was blunt trauma due to motor vehicle collision $(40.4 \%)$. Clinical outcomes were poor (Table 1). Mortality within $48 \mathrm{hr}$ of hospital presentation was $45.0 \%$; overall hospital mortality was $58.5 \%$, and median ICU length of stay was 5 (IQR 1-15.5) days. Among those surviving at least $48 \mathrm{hr}$, ICU length of stay was 13 (IQR 7-25) days. Only 17/260 (6.5\%) patients were discharged home without requiring at least short-term rehabilitation, nursing, or medical support.

Patients received a median of 38 (IQR 25-64) blood components within $48 \mathrm{hr}$ of presentation, including 19 (IQR 14-28) red blood cell units, 10 (IQR 5-15.5) platelet units, 7 (IQR 4-12) fresh frozen plasma units, and 0 (IQR $0-8)$ cryoprecipitate units. Only 1 of the 260 patients received recombinant activated coagulation factor VII.

For patients surviving at least $48 \mathrm{hr}$, independent predictors of higher maximum SOFA score in the ICU were higher age, SOFA score at ICU admission, red blood cell units transfused by $48 \mathrm{hr}$, and lower nadir hemoglobin before $48 \mathrm{hr}$ (Table 2). There was low correlation between nadir hemoglobin and red blood cells transfused (Pearson correlation, -0.27). Other weaker predictors of maximum SOFA included ISS and female sex. Year of hospital admission was not associated with maximum SOFA in patients surviving to $48 \mathrm{hr}$.

Among ICU survivors, ICU length of stay was longer with female gender and with higher ISS, age, and SOFA score at ICU admission (Table 3). (Note that a hazard ratio $<1$ implies a decreased relative hazard of live ICU 
Table 1 Demographics, physiological characteristics, and outcomes of massively transfused trauma patients

$I C U$ intensive care unit; $I Q R$ interquartile range; $S D$ standard deviation; SOFA sequential organ failure assessment ${ }^{12}$

${ }^{a}$ For patients not surviving to ICU admission, the SOFA score was calculated based on available data from the emergency department or operating room

b This category includes occupants of enclosed vehicles with at least four wheels

c SOFA values from day 3 of ICU admission up to and including day of ICU discharge were considered

\begin{tabular}{|c|c|}
\hline Variable & $N=260$ \\
\hline Males & $177(68.1 \%)$ \\
\hline Age, years; median (IQR) & $38(26.5-62.0)$ \\
\hline Injury severity score, mean (SD) & $42.5(15.1)$ \\
\hline SOFA at ICU admission, mean $(\mathrm{SD})^{\mathrm{a}}$ & $8.4(3.8)$ \\
\hline \multicolumn{2}{|l|}{ Mechanism of injury } \\
\hline Motor-vehicle collision $^{\mathrm{b}}$ & $105(40.4 \%)$ \\
\hline Pedestrian & $58(22.3 \%)$ \\
\hline Motorcycle/recreation vehicle & $21(8.1 \%)$ \\
\hline Fall & $21(8.1 \%)$ \\
\hline Industrial accident & $18(6.9 \%)$ \\
\hline Penetrating & $31(11.9 \%)$ \\
\hline Other & $6(2.3 \%)$ \\
\hline \multicolumn{2}{|l|}{ Initial laboratory data } \\
\hline Nadir hemoglobin in the first $48 \mathrm{hr}, \mathrm{g} \cdot \mathrm{L}^{-1}$; mean (SD) & $68(21)$ \\
\hline Platelets, $10^{9} \cdot \mathrm{L}^{-1}$; mean (SD) & $163(89)$ \\
\hline International normalized ratio, median (IQR) $(N=225)$ & $1.45(1.21-1.88)$ \\
\hline \multicolumn{2}{|l|}{ Clinical outcomes (entire cohort) } \\
\hline Died in hospital & $152(58.5 \%)$ \\
\hline Within $48 \mathrm{hr}$ of presentation & $117(45.0 \%)$ \\
\hline In ICU after survival to $48 \mathrm{hr}$ & $32(12.3 \%)$ \\
\hline In hospital after ICU discharge & $3(1.2 \%)$ \\
\hline Discharged alive from hospital & $108(41.5 \%)$ \\
\hline To rehabilitation centre & $63(24.2 \%)$ \\
\hline To home without home care & $17(6.5 \%)$ \\
\hline To home with home care & $12(4.6 \%)$ \\
\hline To other acute care centre & $12(4.6 \%)$ \\
\hline To chronic care facility & $2(0.8 \%)$ \\
\hline Other & $2(0.8 \%)$ \\
\hline Intensive care unit length of stay, days; median (IQR) & $5(1-15.5)$ \\
\hline Hospital length of stay, days; median (IQR) & $7(1-34.5)$ \\
\hline Maximum SOFA score, mean (SD) & $10.1(3.7)$ \\
\hline Clinical outcomes (patients surviving to $48 \mathrm{hr}$ ) & $N=143$ \\
\hline Intensive care unit length of stay, days; median (IQR) & $13(7-25)$ \\
\hline Hospital length of stay, days; median (IQR) & $32(15-51)$ \\
\hline Maximum SOFA score, mean $(\mathrm{SD})^{\mathrm{c}}$ & $8.5(4.2)$ \\
\hline
\end{tabular}

discharge, that is, a longer ICU stay among survivors as the value of the predictor variable increases.) Red blood cell units transfused within $48 \mathrm{hr}$ had no effect on ICU length of stay (hazard ratio $0.99,95 \%$ confidence interval 0.97-1.00), and there was a trend to shorter ICU length of stay with later year of hospital admission. In a secondary analysis imputing values for missing data regarding the number of red blood cell units transfused within $48 \mathrm{hr}$, the hazard ratio for red blood cell transfusion was similar and close to unity, but it became statistically significant (hazard ratio $0.98,95 \%$ confidence interval 0.97-0.99).
Multiple logistic regression showed that higher SOFA at ICU admission and later year of hospital admission were independent predictors of 48-hr mortality (Table 4). Increasing age, ISS, and maximum SOFA during ICU stay were the independent predictors of hospital mortality in patients surviving to $48 \mathrm{hr}$ (Table 5); results of the main and sensitivity analyses were similar. Year of hospital admission was not an independent predictor of hospital mortality among 48-hr survivors. The number of red blood cell units transfused by $48 \mathrm{hr}$ did not predict either 48-hr mortality or hospital mortality among 48-hr survivors. 
Table 2 Predictors of maximum SOFA score in linear regression, including massively transfused trauma patients surviving at least $48 \mathrm{hr}$ $(n=143)$

\begin{tabular}{|c|c|c|c|c|}
\hline \multirow[t]{2}{*}{ Variable } & \multicolumn{2}{|l|}{ Univariable } & \multicolumn{2}{|l|}{ Multivariable } \\
\hline & $\beta$ coefficient (SE) & $P$-value & $\beta$ coefficient (SE) & $P$-value \\
\hline Age & $0.042(0.017)$ & 0.015 & $0.032(0.013)$ & 0.015 \\
\hline Sex (female $v s$ male) & $1.40(0.77)$ & 0.070 & $1.05(0.57)$ & 0.068 \\
\hline Injury severity score & $0.13(0.022)$ & $<0.0001$ & $0.041(0.021)$ & 0.061 \\
\hline SOFA at ICU admission & $0.72(0.098)$ & $<0.0001$ & $0.59(0.097)$ & $<0.0001$ \\
\hline Nadir hemoglobin before $48 \mathrm{hr}$ & $-0.071(0.019)$ & 0.0003 & $-0.034(0.016)$ & 0.030 \\
\hline Red blood cell units transfused by $48 \mathrm{hr}$ & $0.087(0.018)$ & $<0.0001$ & $0.075(0.015)$ & $<0.0001$ \\
\hline Year of hospital admission & $-0.068(0.13)$ & 0.60 & $-0.14(0.10)$ & 0.17 \\
\hline
\end{tabular}

Maximum SOFA score was calculated from SOFA values from day 3 of ICU admission up to and including day of ICU discharge. For a given continuous predictor variable, the $\beta$ coefficient in the multivariable linear regression model represents the increase in maximum SOFA score when the predictor variable increases by one unit and all other variables in the model are held constant. There was low correlation between nadir hemoglobin before $48 \mathrm{hr}$ and red blood cell units transfused by $48 \mathrm{hr}$ (Pearson correlation, -0.27). The coefficient of determination for the multivariable linear regression model is $R^{2}=52.4 \%$

$I C U$ intensive care unit; $S E$ standard error; SOFA sequential organ failure assessment

Table 3 Predictors of ICU length of stay in transfused trauma patients surviving to $48 \mathrm{hr}(n=131)$

\begin{tabular}{|c|c|c|c|c|}
\hline \multirow[t]{2}{*}{ Variable } & \multicolumn{2}{|l|}{ Univariable } & \multicolumn{2}{|l|}{ Multivariable } \\
\hline & HR $(95 \%$ CI $)$ & $P$-value & HR $(95 \%$ CI $)$ & $P$-value \\
\hline Age & $0.98(0.97,0.99)$ & $<0.0001$ & $0.98(0.97-0.99)$ & 0.0015 \\
\hline Sex (female $v s$ male) & $0.52(0.35,0.77)$ & 0.0011 & $0.46(0.29-0.74)$ & 0.0012 \\
\hline Injury severity score & $0.94(0.92,0.95)$ & $<0.0001$ & $0.94(0.93-0.96)$ & $<0.0001$ \\
\hline SOFA at ICU admission & $0.85(0.80,0.90)$ & $<0.0001$ & $0.88(0.82-0.95)$ & 0.00034 \\
\hline Nadir hemoglobin before $48 \mathrm{hr}$ & $1.01(1.00,1.02)$ & 0.21 & $1.01(0.99-1.02)$ & 0.28 \\
\hline Red blood cell units transfused by $48 \mathrm{hr}$ & $0.98(0.96,1.00)$ & 0.018 & $0.99(0.97-1.00)$ & 0.14 \\
\hline Year of hospital admission & $1.00(0.94,1.07)$ & 0.91 & $1.09(1.00-1.20)$ & 0.059 \\
\hline
\end{tabular}

A Fine and Gray survival model was used to analyze the outcome of ICU length of stay, with death as a competing risk. ${ }^{21} \mathrm{HR}<1$ implies a decreased relative hazard of live ICU discharge, that is, a longer ICU stay among survivors as the value of the predictor variable increases. For continuous predictor variables, HR refers to a 1-unit increment. The analysis excluded patients with missing data on red blood cell units transfused by $48 \mathrm{hr}(n=12)$. If these patients are included by substituting the total number of red blood cell units transfused for the entire hospital stay, the effect of red blood cells transfused by $48 \mathrm{hr}$ is similar in magnitude but becomes significant: HR 0.98, 95\% CI 0.97-0.99; $P<0.0001$. Other HRs do not change. There was low correlation between nadir hemoglobin before $48 \mathrm{hr}$ and red blood cell units transfused by $48 \mathrm{hr}$ (Pearson correlation, -0.27 )

$C I$ confidence interval; $H R$ hazard ratio; ICU intensive care unit; SOFA sequential organ failure assessment

\section{Discussion}

As part of a quality improvement project initiated in 2003, we examined a cohort of massively transfused trauma patients from a busy Canadian trauma centre over a 10-year period (1992-2001). Patients received a median of 38 blood components within $48 \mathrm{hr}$ of presentation, half of which were red blood cell units. Early mortality was high. The novel contribution of our analysis was to examine the effect of red blood cell transfusion by injury phase. Among patients surviving the resuscitation phase to $48 \mathrm{hr}$, we found that early red blood cell transfusion independently predicted maximum organ dysfunction but not hospital mortality, after adjusting for initial trauma and illness severity. There was no independent effect on 48-hr mortality. Overall, our data suggest that early massive transfusion is associated with worse organ dysfunction in the ICU, but not increased early mortality or hospital mortality among those surviving initial resuscitation.

In contrast, other studies in traumatically injured patients have found an independent association of red blood cell transfusion on mortality, ${ }^{10,17-20,26}$ with most hemorrhage-related deaths occurring within $24 \mathrm{hr}$ of trauma. ${ }^{4}$ This association has been described in patients with primarily blunt trauma ${ }^{10,19}$ and in mixed populations with $\sim 20 \%$ penetrating trauma. ${ }^{17,18,20}$ These studies have also demonstrated patient age and severity of injury and illness to predict hospital mortality, raising the possibility 
Table 4 Predictors of 48-hr mortality $(n=117)$ in logistic regression, including massively transfused trauma patients $(n=260)$

\begin{tabular}{|c|c|c|c|c|}
\hline Variable & $\begin{array}{l}\text { Univariable } \\
\text { OR }(95 \% \text { CI) }\end{array}$ & $P$-value & $\begin{array}{l}\text { Multivariable } \\
\text { OR }(95 \% \text { CI })\end{array}$ & $P$-value \\
\hline Age & $1.00(0.99-1.01)$ & 0.61 & $0.99(0.97,1.01)$ & 0.17 \\
\hline Sex (female $v s$ male) & $1.30(0.77-2.19)$ & 0.33 & $1.50(0.76,2.99)$ & 0.24 \\
\hline Injury severity score & $1.04(1.02-1.06)$ & $<0.0001$ & $1.00(0.98,1.03)$ & 0.76 \\
\hline SOFA at ICU admission & $1.62(1.44-1.82)$ & $<0.0001$ & $1.65(1.45,1.88)$ & $<0.0001$ \\
\hline Red blood cell units transfused by $48 \mathrm{hr}^{\mathrm{a}}$ & $0.995(0.98,1.01)$ & 0.52 & $0.98(0.96,1.01)$ & 0.24 \\
\hline Total blood components transfused by $48 \mathrm{hr}$ & $0.991(0.985,0.998)$ & 0.0093 & Not entered ${ }^{\mathrm{b}}$ & \\
\hline Year of hospital admission & $1.15(1.05,1.25)$ & 0.0024 & $1.15(1.02,1.29)$ & 0.025 \\
\hline
\end{tabular}

For continuous variables, OR refers to a 1-unit increment. There was no evidence of lack of fit for this model (Hosmer-Lemeshow $P$-value, 0.32 ). Regression diagnostics showed the death of one case with a high residual and a low probability of hospital mortality. Removing this case did not change the ORs

$C I$ confidence interval; ICU intensive care unit; $O R$ odds ratio; SOFA sequential organ failure assessment

${ }^{a}$ Expressed in an increment of 5 red blood cell units, the corresponding OR (95\% CI) is as follows: univariable model, 0.97 (0.90, 1.06$)$; and multivariable model, $0.92(0.80,1.06)$

b This variable was not entered into the model because it was highly collinear (Pearson correlation, 0.90) with red blood cell units transfused by $48 \mathrm{hr}$

Table 5 Predictors of hospital mortality $(n=35)$ in logistic regression including massively transfused trauma patients surviving at least $48 \mathrm{hr}$ $(n=143)$

\begin{tabular}{|c|c|c|c|c|c|c|}
\hline \multirow[t]{2}{*}{ Variable } & \multicolumn{2}{|l|}{ Univariable } & \multicolumn{4}{|l|}{ Multivariable $^{\mathrm{a}}$} \\
\hline & OR $(95 \% \mathrm{CI})$ & $P$-value & $\begin{array}{l}\text { Main model; } \\
\text { OR }(95 \% \mathrm{CI})\end{array}$ & $P$-value & $\begin{array}{l}\text { Sensitivity model; } \\
\text { OR }(95 \% \mathrm{CI})\end{array}$ & $P$-value \\
\hline Age & $1.04(1.02-1.07)$ & $<0.0001$ & $1.06(1.03-1.10)$ & 0.0001 & $1.06(1.03-1.09)$ & 0.0003 \\
\hline Sex (female $v s$ male) & $1.61(0.72-3.61)$ & 0.25 & Not entered & & $1.21(0.38,3.82)$ & 0.75 \\
\hline Injury severity score & $1.08(1.04-1.12)$ & $<0.0001$ & $1.07(1.02-1.13)$ & 0.0067 & $1.08(1.02,1.13)$ & 0.0049 \\
\hline SOFA at ICU admission & $1.32(1.14-1.52)$ & 0.0002 & Not entered & & & \\
\hline Maximum SOFA during ICU stay ${ }^{\mathrm{b}}$ & $1.49(1.29-1.73)$ & $<0.0001$ & $1.56(1.27-1.93)$ & $<0.0001$ & $1.54(1.24,1.91)$ & $<0.0001$ \\
\hline Nadir hemoglobin before $48 \mathrm{hr}$ & $0.96(0.94-0.98)$ & 0.0012 & Not entered & & $0.98(0.95,1.02)$ & 0.26 \\
\hline Red blood cell units transfused by $48 \mathrm{hr}^{\mathrm{c}}$ & $1.019(0.999-1.039)$ & 0.057 & $1.01(0.97-1.05)$ & 0.61 & $1.00(0.97,1.04)$ & 0.84 \\
\hline Total blood components transfused by $48 \mathrm{hr}$ & $1.009(1.002-1.015)$ & 0.007 & Not entered & & & \\
\hline Year of hospital admission & $1.1(0.96,1.26)$ & 0.18 & $1.11(0.90-1.38)$ & 0.34 & $1.08(0.86,1.36)$ & 0.49 \\
\hline
\end{tabular}

CI confidence interval; ICU intensive care unit; OR odds ratio; SOFA sequential organ failure assessment

${ }^{a}$ Because the multiple logistic regression model contained only 35 deaths, we decided a priori to include only five clinically important variables in the main model (seven events per variable). In a sensitivity analysis, we entered two other variables into the model (five events per variable). The following variables were highly collinear: red blood cell units transfused and total blood components transfused (Pearson correlation, 0.91), and maximum SOFA during ICU stay and SOFA at ICU admission (Pearson correlation, 0.65). For each model, we entered the first variable in each pair. There was low correlation between nadir hemoglobin before $48 \mathrm{hr}$ and red blood cell units transfused by $48 \mathrm{hr}$ (Pearson correlation, -0.27 ). For continuous variables, OR refers to a 1-unit increment. There was evidence of lack of fit for the main model (Hosmer-Lemeshow $P$-value, 0.03 ), but not the sensitivity model (Hosmer-Lemeshow $P$-value, 0.68 ). Regression diagnostics showed the death of two cases with high residuals, both with a low probability of hospital mortality. Removing these cases did not substantially change the odds ratios but improved the fit of the main model (Hosmer-Lemeshow P-value, 0.26). Results of the two models were consistent

${ }^{\mathrm{b}}$ SOFA values from day of ICU admission up to and including day of ICU discharge were considered

${ }^{c}$ Expressed in an increment of 5 red blood cell units, the corresponding OR (95\% CI) is as follows: univariable model, 1.10 (1.00, 1.21); main multivariable model, $1.05(0.88,1.26)$; and sensitivity multivariable model, $1.02(0.84,1.24)$

that the association of red blood cell transfusion with early mortality may stem from residual confounding due to the severity of the underlying injury or illness rather than an independent adverse effect of transfusion.

Our study has several potential sources of bias. First, we may have underestimated the association between early red blood cell transfusion and early mortality due to the effect of immortal time bias. Analyzing transfusion as a timedependent variable would have increased the odds ratio, although the magnitude of the change cannot be predicted. In other observational studies that observed a positive association between red blood cell transfusion and 
mortality, correct handling of this bias would simply have increased the magnitude of the association. Another method of addressing this bias is to restrict the analysis to patients who survive the time period that data on the exposure variable are collected. In our dataset, red blood cell transfusion had a consistent lack of independent effect on 48-hr mortality in all patients and on hospital mortality in patients surviving to $48 \mathrm{hr}$. This consistency somewhat mitigates the concern that immortal time bias influenced the 48-hr mortality analysis. Second, despite inclusion of measures of severity of injury and initial and subsequent critical illness, residual confounding due to unmeasured known confounders (such as presence of severe head injury $^{5}$ and a more detailed acute illness severity score ${ }^{27}$ ) is possible. Although larger datasets may overcome the problem of residual confounding by permitting more sophisticated methods of adjustment, ${ }^{28}$ collecting the necessary detailed patient-level data becomes more challenging. Third, the overall study sample was relatively small, and the analysis of hospital mortality had few outcome events. Although the best estimate of the effect of red blood cell transfusion on hospital mortality is close to nil and the confidence intervals are tight, they refer to one additional red blood cell unit transfused. Considering an increment of 5 red blood cell units as clinically relevant in a massively transfused population, multivariable analysis showed that the $95 \%$ confidence interval included effect estimates ranging from a $12-16 \%$ decrease to a $24-26 \%$ increase in the odds of hospital mortality.

Among patients surviving to $48 \mathrm{hr}$, early red blood cell transfusion increased maximum organ dysfunction in the ICU and may have been associated with a marginal increase in ICU length of stay among survivors. The statistical significance of the latter finding depended on whether patients with missing data on the number of red blood cell units transfused were included with imputed values or simply dropped, although the absolute effect was similar and extremely small in magnitude in both analyses. Potential causes of delayed morbidity include acute lung injury, ${ }^{6,7}$ infection, ${ }^{8-10}$ and multiple organ failure ${ }^{10,11}$ mediated by pro-inflammatory effects of leukocytes. ${ }^{29}$

We found several other noteworthy associations. First, later year of hospital admission was associated with higher 48-hr mortality. Possible explanations include increasing injury and illness severity over time, evolving clinical care practices (such as more intensive pre-hospital medical care introduced during the study period), ${ }^{30}$ or changes in blood product characteristics (such as longer storage time prior to transfusion). We did not consider interactions between illness severity and year of admission in our pre-specified analysis plan, and these associations may not be detected by underpowered statistical tests of interaction. ${ }^{31}$ Similarly, we did not document clinical care practices, such as time to operative intervention, time to transfusion, or staffing patterns. Later year of hospital admission was also associated with a trend to shorter ICU stay among patients surviving to $48 \mathrm{hr}$. Possible explanations include increasing demand for ICU resources leading to earlier ICU discharge or better general care leading to fewer complications. Unfortunately, our dataset cannot investigate these hypotheses.

Second, female sex was a borderline statistically significant risk factor for an increased maximum SOFA score, but it was a clear predictor of increased ICU length of stay among 48-hr survivors. In contrast, previous studies have found sepsis and multiple organ dysfunction to be less common in females after traumatic injuries. ${ }^{32,33}$ Patients in our analyses who survived to $48 \mathrm{hr}$ may resemble the generally critically ill population in which older women have a higher risk of ICU mortality compared with older men. $^{34}$

Finally, there was only a weak inverse correlation between nadir hemoglobin and red blood cell units transfused in the analysis of hospital mortality in 48-hr survivors. Possible explanations include failure to detect critical anemia in massively bleeding patients due to rapid resuscitative transfusion or inappropriate transfusion practice. We did not have detailed reliable information on hemoglobin values to judge transfusion appropriateness by laboratory criteria.

Recent efforts to improve outcomes for patients who are transfused blood products are focused on leukoreduction, earlier transfusion of clotting factors, and use of fresher red blood cell units. First, investigators have found that prestorage centrifugation or filtration of red blood cell units removes $99.995 \%$ of leukocytes, ${ }^{35}$ reducing the concentration of bioactive lipids and inflammatory cytokines. ${ }^{36-38}$ To attenuate the potential harmful effects of red blood cell transfusion, universal pre-storage leukoreduction was introduced in Canada in July 1999. However, despite considerable theoretical advantages, clinical benefits of leukoreduction have been inconsistent in observational studies ${ }^{39-41}$ and randomized trials. ${ }^{42-44}$ In our study, later year of hospital admission was not associated with improved outcomes. However, our dataset is underpowered to examine the effect of leukoreduction specifically, since relatively few patients ( $\sim 20 \%$ ) were included in the post-leukoreduction period.

Second, emerging research suggests that early correction of coagulopathy with fresh frozen plasma, transfused together with red blood cell units in a ratio near 1:1, may improve survival in massively transfused patients. Several retrospective cohort studies have found substantial survival gains with this approach in both military ${ }^{45}$ and civilian ${ }^{46-48}$ trauma settings. More recently, however, other investigators ${ }^{49}$ have not confirmed this finding when applying statistical techniques to correct for immortal time bias. ${ }^{25,26}$ Unfortunately, our dataset did not have sufficiently robust 
information on times of transfusion and death to explore this hypothesis in a methodologically sound fashion.

Finally, recent basic science and clinical research has identified a potentially harmful "storage lesion" in transfused red blood cell units. ${ }^{13,50}$ These biochemical and physical changes include intracellular 2,3-diphosphoglycerate depletion that decreases oxygen offloading from hemoglobin, a stiffer cell membrane that reduces red blood cell flow through capillaries, and decreased bioavailability of nitric oxide necessary for microcirculatory vasodilation. These alterations, together with other biological substances present in preserved red blood cell units, may reduce oxygen delivery and stimulate inflammatory pathways. Observational studies in trauma patients $^{51-53}$ support these physiologic data by suggesting adverse clinical outcomes from the use of older rather than fresher red blood cell units, and a large randomized trial investigating the effect of red blood cell unit storage time on clinical outcomes in critically ill patients is ongoing (ISRCTN44878718; details available at www.controlledtrials.com). In our study, we did not collect data on pretransfusion storage time of red blood cell units.

Strengths of our study are the inclusion of critically ill trauma patients (excluding non-massively transfused patients with a better prognosis), a 10-year observation period, and detailed patient-level measures of severity of illness and organ dysfunction calculated for each day of stay in the ICU. Locally, this project led to closer coordination among team members responsible for transfusion decision-making (trauma surgeon, anesthesiologist, intensivist, hematologist, blood bank, and clinical laboratory) and a renewed clinical and research focus on massive transfusion in trauma patients. A locally relevant quality improvement question is whether transfusion patterns and outcomes in severely injured trauma patients have changed as a result of these modifications.

Our study also has limitations. It was initiated as a quality improvement project to better understand local blood product utilization, and the results reflect current practice at the time (8-18 years ago). Since this study, pre-hospital trauma care, ${ }^{30}$ surgical management of trauma, ${ }^{54}$ and intensive care staffing ${ }^{55}$ have all evolved, and Canadian physicians have adopted a more conservative approach to red blood cell transfusion in critically ill patients. ${ }^{56}$ However, the trend to declining injury-related deaths in Canada during the study period may be due to prevention initiatives rather than to advances in the care of trauma patients. ${ }^{2}$ In addition, the evidence base, attitudes, beliefs, and practices for transfusion in acute trauma resuscitation are not wellcharacterized. Therefore, our results likely remain relevant to the care of these patients today.

The data collection was retrospective, leading to incomplete ascertainment of all potentially important covariates. We did not collect data on excluded patients (mostly due to missing laboratory data) who may have had different characteristics or outcomes. Among included patients, missing data on red blood cell transfusions influenced only the secondary analysis of ICU length of stay. We did not examine a comprehensive set of clinical outcomes, such as infectious complications and acute lung injury. Finally, research in a more contemporaneous population of massively transfused patients in additional centres would be required to confirm or refute our hospital's findings. Our modelling techniques may help others interested in exploring similar associations at their own centres.

In conclusion, we found that the volume of early red blood cell transfusion is associated with increased organ dysfunction but not hospital mortality among patients surviving the first 48-hr resuscitation phase. Early mortality is high among the massively transfused patients with traumatic injury, but it is not associated with early red blood cell transfusion. Further basic science and clinical studies should (1) examine these associations in different trauma cohorts; (2) elucidate the mechanisms of potentially delayed adverse effects of transfusion; and (3) evaluate potential mitigating interventions, such as fresh blood component transfusion ${ }^{57}$ and protocols designed to limit over-transfusion. ${ }^{58}$

Acknowledgements We thank Martin Chapman for assistance with study design, Nicole Mittmann for assistance with database management and for comments on an earlier draft of this manuscript, and Cyndy Rogers for assistance with trauma database queries.

Funding This study received no funding.

Competing interests None declared.

\section{References}

1. World Health Organization. World Health Statistics 2008. Available from URL: http://www.who.int/whosis/whostat/2008/ en/index.html. Accessed June 2009.

2. Simons RK. Injury control and trauma care in Canada: how well are we doing? Trauma Association of Canada Presidential address. J Trauma 2006; 61: 1027-35.

3. Tien H, Nascimento B Jr, Callum J, Rizoli S. An approach to transfusion and hemorrhage in trauma: current perspectives on restrictive transfusion strategies. Can J Surg 2007; 50: 202-9.

4. Hoyt DB, Bulger EM, Knudson MM, et al. Death in the operating room: an analysis of a multi-center experience. J Trauma 1994; 37: 426-32.

5. Sauaia A, Moore FA, Moore EE, et al. Epidemiology of trauma deaths: a reassessment. J Trauma 1995; 38: 185-93.

6. Miller PR, Croce MA, Kilgo PD, Scott J, Fabian TC. Acute respiratory distress syndrome in blunt trauma: identification of independent risk factors. Am Surg 2002; 68: 845-50; discussion $850-1$.

7. Silverboard H, Aisiku I, Martin GS, Adams M, Rozycki G, Moss $M$. The role of acute blood transfusion in the development of 
acute respiratory distress syndrome in patients with severe trauma. J Trauma 2005; 59: 717-23.

8. Claridge JA, Sawyer RG, Schulman AM, McLemore EC, Young $J S$. Blood transfusions correlate with infections in trauma patients in a dose-dependent manner. Am Surg 2002; 68: 566-72.

9. Hill GE, Frawley WH, Griffith KE, Forestner JE, Minei JP. Allogeneic blood transfusion increases the risk of postoperative bacterial infection: a meta-analysis. J Trauma 2003; 54: 908-14.

10. Huber-Wagner S, Qvick M, Mussack T, et al. Massive blood transfusion and outcome in 1062 polytrauma patients: a prospective study based on the Trauma Registry of the German Trauma Society. Vox Sang 2007; 92: 69-78.

11. Moore FA, Moore EE, Sauaia A. Blood transfusion. An independent risk factor for postinjury multiple organ failure. Arch Surg 1997; 132: 620-4; discussion 624-5.

12. Vincent JL, Moreno R, Takala J, et al. The SOFA (Sepsis-related Organ Failure Assessment) score to describe organ dysfunction/ failure On behalf of the Working Group on Sepsis-Related Problems of the European Society of Intensive Care Medicine. Intensive Care Med 1996; 22: 707-10.

13. Shaz BH, Dente CJ, Harris RS, MacLeod JB, Hillyer CD. Transfusion management of trauma patients. Anesth Analg 2009; 108: 1760-8.

14. Baker SP, O'Neill B, Haddon W Jr, Long WB. The injury severity score: a method for describing patients with multiple injuries and evaluating emergency care. J Trauma 1974; 14: 187-96.

15. Moreno $R$, Vincent $J L$, Matos $R$, et al. The use of maximum SOFA score to quantify organ dysfunction/failure in intensive care Results of a prospective, multicentre study. Working Group on Sepsis related Problems of the ESICM. Intensive Care Med 1999; 25: 686-96.

16. Ferreira FL, Bota DP, Bross A, Melot C, Vincent JL. Serial evaluation of the SOFA score to predict outcome in critically ill patients. JAMA 2001; 286: 1754-8.

17. Rizoli SB, Nascimento B Jr, Osman F, et al. Recombinant activated coagulation factor VII and bleeding trauma patients. J Trauma 2006; 61: 1419-25.

18. Malone DL, Dunne J, Tracy JK, Putnam AT, Scalea TM, Napolitano LM. Blood transfusion, independent of shock severity, is associated with worse outcome in trauma. J Trauma 2003; 54: 898-905; discussion 905-7.

19. Robinson WP 3rd, Ahn J, Stiffler A, et al. Blood transfusion is an independent predictor of increased mortality in nonoperatively managed blunt hepatic and splenic injuries. J Trauma 2005; 58: 437-44; discussion 444-5.

20. Mostafa G, Gunter OL, Norton HJ, McElhiney BM, Bailey DF, Jacobs $D G$. Age, blood transfusion, and survival after trauma. Am Surg 2004; 70: 357-63.

21. Fine J, Gray R. A proportional hazards model for the subdistribution of a competing risk. J Am Stat Assoc 1999; 94: 496-509.

22. Harrell FE Jr, Lee KL, Matchar DB, Reichert TA. Regression models for prognostic prediction: advantages, problems, and suggested solutions. Cancer Treat Rep 1985; 69: 1071-7.

23. Vittinghoff E, McCulloch CE. Relaxing the rule of ten events per variable in logistic and Cox regression. Am J Epidemiol 2007; 165: 710-8.

24. Pintilie M. Competing Risks: A Practical Perspective. Hoboken, NJ: John Wiley \& Sons; 2006.

25. Suissa $S$. Immortal time bias in pharmaco-epidemiology. Am J Epidemiol 2008; 167: 492-9.

26. van Walraven C, Davis D, Forster AJ, Wells GA. Time-dependent bias was common in survival analyses published in leading clinical journals. J Clin Epidemiol 2004; 57: 672-82.

27. Knaus WA, Draper EA, Wagner DP, Zimmerman JE. APACHE II: a severity of disease classification system. Crit Care Med 1985; 13: $818-29$.
28. Wunsch H, Linde-Zwirble WT, Angus DC. Methods to adjust for bias and confounding in critical care health services research involving observational data. J Crit Care 2006; 21: 1-7.

29. Nielsen HJ, Reimert CM, Pedersen AN, et al. Time-dependent, spontaneous release of white cell- and platelet-derived bioactive substances from stored human blood. Transfusion 1996; 36: 960-5.

30. Stiell IG, Nesbitt LP, Pickett W, et al. The OPALS Major Trauma Study: impact of advanced life-support on survival and morbidity. CMAJ 2008; 178: 1141-52.

31. Schulz KF, Grimes DA. Multiplicity in randomised trials II: subgroup and interim analyses. Lancet 2005; 365: 1657-61.

32. Oberholzer A, Keel M, Zellweger R, Steckholzer U, Trentz O, Ertel $W$. Incidence of septic complications and multiple organ failure in severely injured patients is sex specific. J Trauma 2000; 48: 932-7.

33. Sperry JL, Nathens AB, Frankel HL, et al. Characterization of the gender dimorphism after injury and hemorrhagic shock: are hormonal differences responsible? Crit Care Med 2008; 36: 1838-45.

34. Fowler RA, Sabur N, Li P, et al. Sex-and age-based differences in the delivery and outcomes of critical care. CMAJ 2007; 177: 1513-9.

35. Shapiro MJ. To filter blood or universal leukoreduction: what is the answer? Crit Care 2004; 8(Suppl 2): S27-30.

36. Kristiansson M, Soop M, Shanwell A, Sundqvist KG. Prestorage versus bedside white blood cell filtration of red blood cell concentrates: effects on the content of cytokines and soluble tumor necrosis factor receptors. J Trauma 1996; 40: 379-83.

37. Shanwell A, Kristiansson $M$, Remberger M, Ringden O. Generation of cytokines in red cell concentrates during storage is prevented by prestorage white cell reduction. Transfusion 1997; 37: $678-84$.

38. Sparrow RL, Patton KA. Supernatant from stored red blood cell primes inflammatory cells: influence of prestorage white cell reduction. Transfusion 2004; 44: 722-30.

39. Friese RS, Sperry JL, Phelan HA, Gentilello LM. The use of leukoreduced red blood cell products is associated with fewer infectious complications in trauma patients. Am J Surg 2008; 196: 56-61.

40. Plurad D, Belzberg H, Schulman I, et al. Leukoreduction is associated with a decreased incidence of late onset acute respiratory distress syndrome after injury. Am Surg 2008; 74: 117-23.

41. Phelan HA, Sperry JL, Friese RS. Leukoreduction before red blood cell transfusion has no impact on mortality in trauma patients. J Surg Res 2007; 138: 32-6.

42. Nathens AB, Nester TA, Rubenfeld GD, Nirula R, Gernsheimer $T B$. The effects of leukoreduced blood transfusion on infection risk following injury: a randomized controlled trial. Shock 2006; 26: $342-7$

43. Vamvakas EC. White-blood-cell-containing allogeneic blood transfusion and postoperative infection or mortality: an updated meta-analysis. Vox Sang 2007; 92: 224-32.

44. Watkins TR, Rubenfeld GD, Martin TR, et al. Effects of leukoreduced blood on acute lung injury after trauma: a randomized controlled trial. Crit Care Med 2008; 36: 1493-9.

45. Borgman MA, Spinella PC, Perkins JG, et al. The ratio of blood products transfused affects mortality in patients receiving massive transfusions at a combat support hospital. J Trauma 2007; 63: 805-13.

46. Gunter OL Jr, Au BK, Isbell JM, Mowery NT, Young PP, Cotton $B A$. Optimizing outcomes in damage control resuscitation: identifying blood product ratios associated with improved survival. J Trauma 2008; 65: 527-34.

47. Duchesne JC, Hunt JP, Wahl G, et al. Review of current blood transfusions strategies in a mature level I trauma center: were we wrong for the last 60 years? J Trauma 2008; 65: 272-6. 
48. Kashuk JL, Moore EE, Johnson JL, et al. Postinjury life threatening coagulopathy: is 1:1 fresh frozen plasma:packed red blood cells the answer? J Trauma 2008; 65: 261-70.

49. Snyder $C W$, Weinberg JA, McGwin G Jr, et al. The relationship of blood product ratio to mortality: survival benefit or survival bias? J Trauma 2009; 66: 358-62.

50. Tinmouth A, Fergusson D, Yee IC, Hebert PC; ABLE Investigators Critical Care Trials Group. Clinical consequences of red cell storage in the critically ill. Transfusion 2006; 46: 2014-27.

51. Offner PJ, Moore EE, Biff WL, Johnson JL, Silliman CC. Increased rate of infection associated with transfusion of old blood after severe injury. Arch Surg 2002; 137: 711-6.

52. Keller ME, Jean R, LaMorte WW, Millham F, Hirsch E. Effects of age of transfused blood on length of stay in trauma patients: a preliminary report. J Trauma 2002; 53: 1023-5.

53. Zallen G, Offner PJ, Moore EE, et al. Age of transfused blood is an independent risk factor for postinjury multiple organ failure. Am J Surg 1999; 178: 570-2.
54. Germanos $S$, Gourgiotis $S$, Villias $C$, Bertucci M, Dimopoulos N, Salemis $N$. Damage control surgery in the abdomen: an approach for the management of severe injured patients. Int J Surg 2008; 6: 246-52.

55. Pronovost PJ, Angus DC, Dorman T, Robinson KA, Dremsizov TT, Young TL. Physician staffing patterns and clinical outcomes in critically ill patients: a systematic review. JAMA 2002; 288: 2151-62.

56. Hebert PC, Fergusson DA, Stather D, et al. Revisiting transfusion practices in critically ill patients. Crit Care Med 2005; 33: 7-12.

57. Hebert PC, ChinYee I, Fergusson D, et al. A pilot trial evaluating the clinical effects of prolonged storage of red cells. Anesth Analg 2005; 100: 1433-8.

58. Cotton BA, Gunter OL, Isbell J, et al. Damage control hematology: the impact of a trauma exsanguination protocol on survival and blood product utilization. J Trauma 2008; 64: 1177-82; discussion 1182-3. 